\title{
Automation of Aseptic Sterile Preparation: Risk Analysis and Productivity Comparison with Manual Process
}

https://doi.org/10.1515/pthp-2019-0001

Received January 17, 2019; revised March 18, 2019; accepted March 18, 2019

\begin{abstract}
Two automation methods for aseptic preparation in hospital pharmacy, robot and peristaltic pump, were compared to manual process both for risk analysis using Failure Modes Effects and Criticality Analysis (FMECA) method and for productivity using time analysis grids built for each process.

The results obtained with the different workflow organizations showed that the worst-case conditions for productivity was production "on demand" of tailormade preparations. in that case, the manual process was not significantly different from the robotic process ( $p$-value $=0.72)$. For the standardized preparations, the semi-automatic process preparing a batch from bulk solution from "to be reconstituted" drugs was significantly superior to the robotic process preparing repetitive series of doses ( $p$-value $<0.01$ ). Productivity of the robot was dramatically increased when the robot performed standardized preparations either from ready to use solutions or mixed cycles due to the robot design. When different processes
\end{abstract}

*Corresponding author: Sylvie Crauste-Manciet, Pharmaceutical Technology Department, Bordeaux University Hospital, Bordeaux, France; ARNA laboratory ChemBioPharm U1212 INSERM - UMR 5320 CNRS, Bordeaux University, Bordeaux, France,

E-mail: sylvie.crauste-manciet@chu-bordeaux.fr

Jeanne Heloury, Pharmaceutical Technology Department, Bordeaux University Hospital, Bordeaux, France,

E-mail: jeanne.heloury@u-bordeaux.fr

Guillaume Bouguéon, Pharmaceutical Technology Department, Bordeaux University Hospital, Bordeaux, France; ARNA laboratory ChemBioPharm U1212 INSERM - UMR 5320 CNRS, Bordeaux University, Bordeaux, France,

E-mail: guillaume.bougueon@chu-bordeaux.fr

Thomas Deljehier, Pharmaceutical Technology Department, Bordeaux University Hospital, Bordeaux, France,

E-mail: thomas.deljehier@chu-bordeaux.fr

Audrey Jourand, Quality department, Bordeaux University Hospital, Bordeaux, France, E-mail: audrey.jourand@chu-bordeaux.fr

Aude Berroneau, Pharmaceutical Technology Department, Bordeaux University Hospital, Bordeaux, France,

E-mail: aude.berroneau@chu-bordeaux.fr were FMECA analyzed for risk analysis the robotic process was found as the safer process in comparison to others with a total of Criticality Indexes of 1060, 719, 656 for manual, semi-automatic and robot, respectively. Except for the robotic, semi-automatic and manual processes needed additional IT control systems to limit the risk of failures.

Keywords: productivity, risk assessment, FMECA, drug compounding, robotics, pharmacy automation

\section{Introduction}

The manual preparation of sterile injectable preparations has always been considered a high-risk activity given the prolonged exposure to dangerous drugs during handling and the extreme personalization of therapies, which multiplies the possibility of error [1]. Different axes were implemented: centralization of the preparations, controls during process or at the end (e. g. human double check, gravimetric control, analytic) and recently the automation [2]. Since the centralization of sterile injectable preparations, our pharmacy has been faced with a constant increase in the number of sterile preparations, without additional human resources, despite the recommendations of scientific societies [3]. To increase productivity, while maintaining the safety and quality of our preparations, our hospital has chosen to move toward to automation of the production. This would reduce the risk of human factors errors, reduce the time required to manufacture preparations and improve work ergonomics. In fact, automation allows improving safety both for operator protection and quality of final product [4]. With regards to operator protection, robot reduces exposition to hazardous drugs [5] and risk for onset of musculoskeletal disorders avoiding manipulator to perform repetitive movements [6]. About the safety of final product, automation allows to ensure a great repeatability in tasks, limit the risk of occurrence of human errors, achieve traceability of each step and perform an in-process control [7]. In this context, the pharmacy implemented a semi-automatic process using a peristaltic pump (Verderflex Vantage $3000^{\circledR}$ ) and a robotic system (KIRO ${ }^{\circledR}$ Oncology robot). 
The preparation of sterile injectable drugs is a complex process due to the multiplicity of actors and steps. The risks for the patient are utmost concern considering the targeted population commonly frail and the diversity of the errors which can be encountered (e. g. microbial contamination of the preparation, error of drug selection or error of final drug quantity) [1, 4]. The increase demand for production pushes the system toward to its limits and may highly compromise the quality. As automation can offer a safe alternative to the manual process currently used in our production departments, it is nowadays required to know the impact of automation on our processes to anticipate problems and find preventive measures in a formal approach way. In this context, our pharmacy realized a risk analysis using Failure Mode, Effects and Criticality Analysis (FMECA) method [8, 9]. This approach allowed to identify potential risks related to each type of process (manual, semi-automatic and robotic) and establish action correctives plans. This risk mapping is then essential in order to identify the processes or interfaces most at risk for greater efficiency.

The aim of our work was to compare three processes (manual, semi-automatic and robotic) for the injectable drugs preparation both for quality and productivity aspects.

\section{Materials and methods}

\section{Definitions of the different categories of preparations and workflow organizations thereof}

An "on demand" tailor-made preparation is a preparation for one patient, with a multitude of available doses calculated on Body Surface Area or by other means.

Dose-banding is a system where doses are fitted to pre-defined dose ranges or "bands". For each band, a standard dose (mid-point of each band) is determined [10]. Standard doses can be potentially produced using two methods: "series" production or batch production from bulk solution. Series production is the repeated production of the same dose individually prepared with different devices and diluents. In that case each individual preparation is considered as a batch. When a bulk solution is used as row material and transferred to several empty bags (or syringes) of the same composition (same volume and dose), a batch corresponds then to more than one bag, and the number of identical bags (or syringes) produced depends on the size of the batch.
Pre-process includes all actions performed before the compounding as clothing, material preparation, reception of production protocol, sterilization cycle when required i. e. when using isolator technology. Per-process corresponds to the act of compounding (i.e. reconstitution, dilution, transfer to final container). Post-process includes all actions performed after the compounding as analytic control of the end-product, preparation release and cleaning.

\section{Workflow organization and the equipments}

Our production unit prepared around 55,000 sterile injectable preparations per year including 34,000 cytotoxics, 9000 monoclonal antibodies and 10,000 antiinfectious drugs. It included 3 separated rooms in controlled atmosphere area (Figure 5).

\section{Manual production controlled area}

Three isolators with 4 workstations were used, one for cytotoxics, one for monoclonal antibodies and one for "on demand" tailor-made cytotoxics with 2 workstations. Isolators were ISO 5 (class A) closed enclosure and were located in an ISO 8 (class D) cleanroom in conformity with French Good Manufacturing Practices (GMPs) for hospital and community pharmacies [11]. When possible, additionally to the per-process visual control, each preparation was subjected to analytical control of the end-product using HPLC-UV detection method or a spectrophotometer UV-Raman (QCRx, Icônes Services, Sucé sur Erdre, France).

\section{Semi-automatic production controlled area}

One isolator (class A) located in ISO 8 (grade D) cleanroom with 2 workstations were available, and one of them was equipped with a peristaltic pump Verderflex ${ }^{\circledR}$ Vantage 3000 (Verder, Eragny-sur-oise, France) (Figure 6). This pump allowed us to compound standardized dose batches from bulk solution either for cytotoxic or anti-infectious drugs. The Verderflex ${ }^{\circledR}$ pump was a peristaltic roller pump system designed for filling bags, syringes, diffusors from drugs and liquid solutions [12]. The pump design was as a one-piece bloc with a numeric keypad on the front panel for controlling and regulating the pump. On the front of the pump, a housing contains the rotating roller, which ensures the transfer of the liquid when the tubing is 
installed. When the bulk big bag is connected to the tubing, it allows the division into a defined number of smaller bags of end-product with a programmable flow and volume. The PcPump ${ }^{\circledR}$ software allows to run the filling process of the bulk bags and end-product bags. A foot pedal is located under the isolator and allows starting or stopping the filling process. The peristaltic pump was chosen according to its compatibility with peracetic acid gazing sterilization process used to enter the isolator through the pass-through. An analytical control with HPLC-UV is performed on the bulk solution to check the final concentration. Then each bag is individually weighted to check the conformity with the expected weight of the final bag end-product.

\section{Robotic production controlled area}

The KIRO ${ }^{\circledR}$ Oncology robot (Kiro Grifols, Arrasate, Spain) was brought through an "innovation market", and enabled to compound sterile drugs including cytotoxics, monoclonal antibodies and anti-infectious drugs. The robot was inside an ISO 5 (grade A) BioSafety Cabinet (BSC) IIb allowing manufacturing sterile injectable preparations. According to the process (closed transfer process) the BSC was located in an ISO 7 (grade C) cleanroom validated in accordance with hospital GMPs [11].

It was fitted with 2 mechanical arms running in parallel to perform different tasks at the same time. Right arm holds vials in order to reconstitute them using 2 peristaltic pumps while left arm holds syringes in order to withdraw the expected dose (Figure 7). The cabinet was only opened for loading and unloading whereas it was closed during the entire compounding and selfcleaning processes allowing protecting operators and environment from exposure to hazardous drugs as well as embedded bins located underneath each arm. The robot was equipped of a self-cleaning process of the enclosure which is run at the end of each working day.

It provided an in-process qualitative and quantitative control allowing checking each step. Qualitative control is ensured by barcode and data matrix readers and cameras located inside the cabinet and in the user area allowing to identify each vial, bag, syringe or others devices used. Furthermore, a datamatrix code is assigned to each material or device entering in the robot allowing to guarantee traceability until preparation release. Quantitative control is provided by a gravimetric method weighting each vial, bag and syringe at each step during the compounding process by internal scale and weighing each final preparation with external scale.
According to the supplier, the KIRO ${ }^{\circledR}$ Oncology system is compatible with many types of final containers (bags, syringes, cassettes and elastomeric pumps) marketed by numerous providers. It allows to use ready to use solutions and powder to be reconstituted. It is able to do on demand tailor-made preparations or standard preparations following a "series production process" (i.e. repetition of the same preparation of same dose in the same final container), but it was currently unsuitable for batch production from bulk solution which will need specific development for both mechanistic and software. A daily process of production includes starting operations (i. e. clothing, manual cleaning, loading of raw material into cleanroom, microbiological sampling), production phase itself including robot cycles and the daily final cleaning (manual cleaning followed by self-cleaning). Cycles were divided in pre-processing phase (preparation of the required material and loading of the robot), automated process in robot and post-processing phase (unloading of the robot, manual external weighing and pharmaceutical validation if necessary).

\section{Productivity assessment of production processes (manual, semi-automatic and robotic)}

The mapping of the three production processes are presented in Table 1. Analysis tables were established to measure time spent to each step according to this mapping for each process. Then, the analysis tables were divided into 3 main phases: pre-process, per-process and post-process. Task's disruptions were observed, like technical failures for automated process.

A junior pharmacist who was not involved in the production collected the data manually with the help of a timer. The data gathering lasted six months for a total of 356 preparations. To measure the activity in similar conditions, time period of observation was set to the morning activity from 8:30 to 12:30 which was always the highest level of activity.

\section{Manual process}

This process was the reference process for the preparations of monoclonal antibodies (bevacizumab, nivolumab, infliximab) produced "on demand" tailor-made. A junior pharmacist (internship) who was not involved in the production collected the data. This process was performed 
Table 1: Mapping of the 3 processes.

\begin{tabular}{|c|c|c|c|c|}
\hline \multirow{2}{*}{$\frac{\text { PROCESS }}{\text { WORKFLOW ORGANIZATION }}$} & \multirow{2}{*}{$\begin{array}{l}\text { MANUAL } \\
\text { "On-demand " } \\
\text { tailor-made }\end{array}$} & \multirow{2}{*}{$\begin{array}{l}\text { SEMI-AUTOMATIC } \\
\text { Standard } \\
\text { (from bulk solution) }\end{array}$} & \multicolumn{2}{|c|}{ ROBOTIC } \\
\hline & & & $\begin{array}{l}\text { "On-demand " } \\
\text { tailor-made }\end{array}$ & $\begin{array}{l}\text { Standard } \\
\text { (series) }\end{array}$ \\
\hline \multicolumn{5}{|l|}{ PRE-PROCESS } \\
\hline \multicolumn{5}{|l|}{ Edit preparation sheets } \\
\hline Check isolator integrity (glove, pressure) & $x$ & $\mathrm{x}$ & & \\
\hline Check BSC runing ventilation & & & $\mathrm{x}$ & $x$ \\
\hline Cleaning workbenches & & $x$ & $\mathrm{x}$ & $\mathrm{x}$ \\
\hline $\begin{array}{l}\text { Preparation of the workload to be introduced } \\
\text { in isolator's hatch (drug, transfer devices, final containers) or } \\
\text { in PSB }\end{array}$ & $\mathrm{x}$ & $\mathrm{x}$ & $\mathrm{x}$ & $\mathrm{x}$ \\
\hline Loading hatch or PSB & $\mathrm{x}$ & $\mathrm{x}$ & $\mathrm{x}$ & $x$ \\
\hline Hatch Sterilization & $\mathrm{x}$ & $\mathrm{x}$ & & \\
\hline \multicolumn{5}{|l|}{ PER-PROCESS } \\
\hline Pump calibration & & $\mathrm{x}$ & & \\
\hline When required reconstitution of drug vial(s) & $\mathrm{x}$ & $\mathrm{x}$ & $\mathrm{x}$ & $x$ \\
\hline Intermediate bulk preparation & & $\mathrm{x}$ & & \\
\hline Transfer of drug solution to final container & $\mathrm{x}$ & $\mathrm{x}$ & $\mathrm{x}$ & $x$ \\
\hline Per process control visual check & $\mathrm{x}$ & $\mathrm{x}$ & & \\
\hline Per process camera / data matrix / identification & & & $x$ & $x$ \\
\hline Per process gravimetric control & & $\mathrm{x}$ & $\mathrm{x}$ & $\mathrm{x}$ \\
\hline Labelling & $\mathrm{x}$ & $\mathrm{x}$ & $x$ & $x$ \\
\hline Sampling for analytical control & $x$ & $x$ & & \\
\hline Sampling for micriobiological control & & $\mathrm{x}$ & & \\
\hline Packaging & $\mathrm{x}$ & $\mathrm{x}$ & $\mathrm{x}$ & $\mathrm{x}$ \\
\hline \multicolumn{5}{|l|}{ POST-PROCESS } \\
\hline Post process gravimetric control & & $\mathrm{x}$ & $x$ & $x$ \\
\hline Analytical control end-product & $\mathrm{x}$ & $\mathrm{x}$ & & \\
\hline Preparation (or batch) release & $\mathrm{x}$ & $\mathrm{x}$ & $\mathrm{x}$ & $\mathrm{x}$ \\
\hline Delivery or storage & $x$ & $x$ & $x$ & $x$ \\
\hline
\end{tabular}

using isolator technology, a sterilization (or disinfection process) was required before entering the isolator. For each preparation, a tray is prepared and combines all materials needed for one preparation (i. e. drug, diluent preparation devices). The time for loading sterilization hatch was divided by the number of contained trays. The sterilization time spent to gas sterilize the hatch workload was not considered as additional time because it was performed simultaneously to other tasks. Similarly, the time for the analytical analysis with analytical device (HPLC-UV or Raman-UV) was not considered. The manual process was based on one operator preparing and a halftime assistant operator for visual in-process controls on 7.5 hour working day without lunch breaktime.

\section{Semi-automatic process - VERDERFLEX ${ }^{\circledR}$ pump}

Three batch productions of an injectable anti-infectious drug (acyclovir) to be reconstituted at one single dose were performed. As previously, the sterilization time and the analysis time by the analytical control device were excluded. The data were collected by the junior pharmacist. The working campaign for one batch production of 50 bags with the pump was based on 1.5 half-time operators.

\section{Robotic process - KIRO ${ }^{\circledR}$ Oncology robot}

For this process, real life "on demand" tailor-made production days of monoclonal antibodies and antiinfectious drugs (bevacizumab, nivolumab, infliximab, acyclovir) were observed by a junior pharmacist, as well as two simulated days of dose standardized preparations (acyclovir) and anticipated preparations (cytotoxics). The first day was performed using single drug, prepared from powder to be reconstituted (acyclovir), at different standardized final doses. The 
second was simulating cytotoxic multi-drugs preparations, prepared from ready-to-use solutions (irinotecan, 5-fluorouracile, gemcitabine and oxaliplatin) at different final standardized doses. Subsequently, two additional days of dose standardized, and anticipated preparations were achieved. These additional days corresponded to two single doses, one prepared from ready-to-use solutions (5-fluorouracile) and one prepared from powder to be reconstituted (cyclophosphamide). This last was defined as a mixed production. The working day was based on 7.5 hours based on a single operator running the robot fulltime (during lunch break time, the operator was switched with another one) and included pre- and post-processing tasks (i.e. clothing, manual cleaning) without any break during lunchtime.

\section{Statistical analysis}

Descriptive statistics (mean, standard deviation (SD)) and simple analyses (Student test) were conducted. A $p$-value $\leq 0.01$ was considered statistically significant.

\section{FMECA risk analysis on the processes}

\section{Choice of risk analysis method and definition of the team}

In accordance with our quality department, we have decided to implement the FMECA method as an analysis tool for our risk mapping. It is indeed the most suitable for the objectives set and especially the most widespread within several sectors of our university hospital. It is a reference method in the medical and hospital world [13]. It was recommended by the Institute Healthcare Improvement (IHI) in United States [8, 9, 14, 15] and by the "Haute Autorite de Santé" (HAS) in France [16]. The major interest of this method is a quantification carried by the criticality index (CI). This takes into account three important parameters in the occurrence of the risk: the frequency, the severity of the effect if it occurs and the possibility of detection before the event occurs. These elements are particularly useful in deciding which steps in the process need to be improved or modified.

We formed a multi-disciplinary team consisting of pharmacy technicians, health manager, senior pharmacists, junior pharmacists assigned to injectable drugs preparation. Once the group was formed, the study managers trained it in the FMECA methodology.

\section{Realization of the risk analysis}

Risk analysis was based on gross criticality approach to determine general criticality to the mentioned risk. Weekly sessions of approximately 45 minutes were planned, a total of 9 sessions were held. The first session was dedicated to train the working group, the $n^{\circ} 2$ and $n^{\circ} 3$ focused on the manual process, a session was needed for the robotic process, and finally three sessions for the semi-automatic process. During these sessions, the group agreed on the chronological sequence of the work steps of each process. Then for each step, in brainstorming session, we asked ourselves "what could go wrong?". Each failure mode was rated using 3 rating parameters (Occurrence (O), severity (S) and detectability(D) by using a consensus risk-rating grid validated by our pharmacy quality department (Figure 1) for the institution. The multiplication of the 3 gave the critically index (CI) of each step. We allowed to use a restricted scoring grid to simplify the analysis and to be in accordance to our institution policies. The use of a restricted scoring grid limited the CI score scale but did not modify the conclusions, as far as the ranking of $\mathrm{CI}$ is the point to be considered in FMEA method more than a value. At the end of each session, an Excel $^{\circledR}$ tool was completed by the junior pharmacist who was one of the project pilots. Then the failure modes were classified according to their CI. During the last session, the most critical ones were exposed to the working group in order to find means of controlling the risk or solutions, and to make them acceptable. Then, each plan was examined with the pharmacists in charge of the production unit to refine its relevance, feasibility, pilots and achievable deadlines. In addition, the root causes of the failure modes were determined using a $5 \mathrm{M}$ diagram. Starting from the identified effect, the analysis is conducted around 5 categories:

- Environment: workstation, physical organization

- Methods: procedures, information flows

- Means/Materials: equipment, machines, tools

- Manpower: human resources, staff qualifications

- Material: consumables, raw materials

Finally, a session was planned to present to the entire production unit team, the action plan drawn up and action plan monitoring indicators selected. 


\begin{tabular}{cl}
\hline Grade & \multicolumn{1}{c}{ OCCURRENCE SCALE } \\
\hline 1 & Low: once or twice a year \\
2 & Moderate: at least once a month \\
3 & High: at least once a week \\
4 & Very high: at least once a day
\end{tabular}

\begin{tabular}{cl}
\hline Grade & \multicolumn{1}{c}{ SEVERITY SCALE } \\
\hline 1 & Minor: failure have no impact on product /patient \\
2 & Low: failure have slight inconvenience on patient / system \\
3 & $\begin{array}{l}\text { Moderate: failure may cause dissatisfaction on patient / system and } \\
\text { needs corrective measure }\end{array}$ \\
4 & High: failure of the product may cause patient damage \\
5 & Very High: failure of the product that may cause patient's death \\
\hline
\end{tabular}

\begin{tabular}{cl}
\hline Grade & \multicolumn{1}{c}{ DETECTION SCALE } \\
\hline 1 & High and very high: current controls almost certain to detect failure \\
2 & $\begin{array}{l}\text { Moderate detection: controls may detect the failure but there is a risk of non- } \\
\text { detection }\end{array}$ \\
3 & Low detection: controls have poor chance to detect the failure \\
4 & Very low or no detection: controls will probably not detect failure \\
\hline
\end{tabular}

Figure 1: Risk scoring grid.

\section{Results}

\section{Productivity assessment of the production processes}

The comparative results between the three processes are summarized in the Table 2. For "on demand" tailor-made preparations, the productivity was not significantly different between the manual process and the robot $(p$-value $=0.72)$ with 5 preparations per hour (3.3 preparations per hour per workforce) and 4 preparations per hour (4 preparations per hour per workforce) respectively. When preparation was standardized, the productivity of the robot performing series preparation was significantly improved in comparison to tailor-made preparation $(\mathrm{p}<0.01)$. This difference can be related to the longer pre-process step explained by the diversity of drugs and devices to be loaded when it was on demand tailor-made preparations in contrast to the standard preparation which involved standard load of drugs and devices.

When it came to comparison of standard preparation of the same drug i.e. acyclovir (drug to be reconstituted) between batch production by the pump and series production by the robot, the results showed that the productivity was significantly higher $(\mathrm{p}<0.01)$ in favor of the pump giving 12 preparations per hour vs. 8 per hour with the robot.

Productivity of the robot was however optimized up to 10 preparations per hour when the robot performed multi-drugs preparations in series, prepared from readyto-use solutions at different final standardized doses and took around $5.5 \mathrm{~min}$, or when drug to be reconstituted

Table 2: Productivity assessment of the 3 processes.

\begin{tabular}{|c|c|c|c|c|}
\hline & MANUAL & ROBOTIC & SEMI-AUTOMATIC & ROBOTIC \\
\hline WORKFLOW ORGANIZATION & $\begin{array}{r}\text { "On-demand " } \\
\text { tailor-made }\end{array}$ & $\begin{array}{r}\text { "On-demand " } \\
\text { tailor-made }\end{array}$ & $\begin{array}{r}\text { Standard } \\
\text { (from bulk solution)* }\end{array}$ & $\begin{array}{r}\text { Standard } \\
\text { (series)* }^{\star}\end{array}$ \\
\hline Workforce (WTE) & $1.5 \pm 0.00$ & $1 \pm 0.00$ & $1.5 \pm 0.00$ & $1 \pm 0,00$ \\
\hline Number of preparations ( $\mathrm{x}$ ) & 38 & 112 & 150 & 56 \\
\hline Observations (n) & 38 & 14 & 3 & 7 \\
\hline Time (min) per preparation & $0: 12: 26 \pm 0: 05: 02$ & $0: 18: 30 \pm 0: 15: 15$ & $0: 05: 06 \pm 0: 00: 21$ & $0: 07: 00 \pm 0: 01: 42$ \\
\hline Number of preparations per hour & $5 \pm 1.77$ & $4 \pm 1.36$ & $12 \pm 0.79$ & $8 \pm 1.88$ \\
\hline Pre-process (min) & $0: 04: 52 \pm 0: 01: 22$ & $0: 27: 45 \pm 0: 09: 04$ & $0: 50: 00 \pm 0: 17: 19$ & $0: 15: 52 \pm 0: 13: 05$ \\
\hline Per-process (min) & $0: 04: 42 \pm 0: 02: 02$ & $0: 24: 19 \pm 0: 01: 39$ & $2: 30: 50 \pm 0: 13: 30$ & $0: 23: 08 \pm 0: 05: 05$ \\
\hline Post-process (min) & $0: 05: 15 \pm 0: 04: 05$ & $0: 07: 12 \pm 0: 01: 32$ & $0: 54: 20 \pm 0: 16: 55$ & $0: 09: 00 \pm 0: 07: 26$ \\
\hline Task’s disruption (min) & $0: 00: 36 \pm 0: 01: 44$ & $0: 05: 38 \pm 0: 00: 47$ & $0: 00: 00 \pm 0: 00: 00$ & $0: 00: 24 \pm 0: 00: 42$ \\
\hline
\end{tabular}

Values are expressed as mean $\pm S D$ of $n$ observations. * drug was a drug to be reconstituted (acyclovir)

WTE: Work Time Equivalent

min: minutes 
were mixed with ready-to-use solutions and took around 5 minutes. Productivity from ready to use or from mixed cycles of ready-to-use and to be reconstituted solutions was not significantly different ( $p$-value $=0.16$ ). When the reconstitution vials step was lacking, the per-process step was faster. However, during mixed production cycles, the reconstitution time did not impact so much the productivity because of the design of the robot allowing both arms to work concurrently.

It was noticeable that the type of preparation impacted task's disruption of the robot with around 5 minutes for tailor-made preparations vs. only 30 second maximum when the robot prepared standard doses. The diversity of the dose-adapted drugs prepared in the tailormade conditions seemed to have negative impact on the number of incidents encountered (e. g. per process needle changes), and on the duration of process disruption.

\section{FMECA risk analysis on the processes}

To carry out this risk analysis, 9 sessions of 45 minutes were necessary. Due to the activity, staff could no longer be available. Throughout the first session, 21 persons working in the unit production were trained at the method. During the next 7 sessions, the 3 processes were reviewed by a multidisciplinary team (pharmacy technicians, health manager, junior pharmacist, senior pharmacist), on average 6 persons were present.

\section{Process mapping}

Before analyzing each process, the working group agreed on the chronological sequence of the work steps. Each process was divided into 3 main steps: pre-process, per- process and post-process. The manual process was divided in 20 sub-steps, in 26 for the semi-automatic process and in 18 for the robotic process.

\section{Failure mode distribution by process step and determination of the risk priority rating (RPN)}

For the "what could get worse" question, the group identified 68 failure modes for the manual process, 79 for the semi-automatic process and 42 for the robotic process. The sum of CI was 1060 for the manual process, 719 for the semi-automatic process and 656 for the robotic process. For each failure mode, the $\mathrm{CI}$ is the product of the $\mathrm{O} \times \mathrm{S} \mathrm{x}$ D scores. Theoretically, the minimal CI of one failure mode was $\mathrm{CI}_{\min }=1 \times 1 \times 1=1(\mathrm{O}=1, \mathrm{~S}=1, \mathrm{D}=1)$ and the maximal $\mathrm{CI}$ of one failure mode was $\mathrm{CI}_{\max }=4 \times 5 \times 4=80(\mathrm{O}=4$, $\mathrm{S}=5, \mathrm{D}=4$ ). In comparison to the manual process, the pump permitted to decrease of $32.2 \%$ the sum of $\mathrm{CI}$ and to $38.1 \%$ with the robot. The ratio number of failures mode on number of sub-steps was 3.2; 3.0 and 2.3; for manual, semi-automatic and robotic process respectively.

The number of failure modes according to process is given in Figure 2. We identified a number of failure above the mean CI (i. e. 16) at 22, 27 and 13; for manual, semi-automatic and robotic process respectively. The Risk Priority Number (RPN) was set at 36 to allow the analyze of failures for the three processes, a higher RPN would had excluded robotic process. The selected RPN allowed us to identify 11 priority failure modes. Ishikawa diagram of failure modes is presented on Figure 3, and a synthesis of their CI are presented in Table 3. Additionally, eight low risk failure modes were considered specifically for the semi-automatic pump which accumulated lots of failures modes in comparison to other processes but mainly with a rate under 36 . Considering

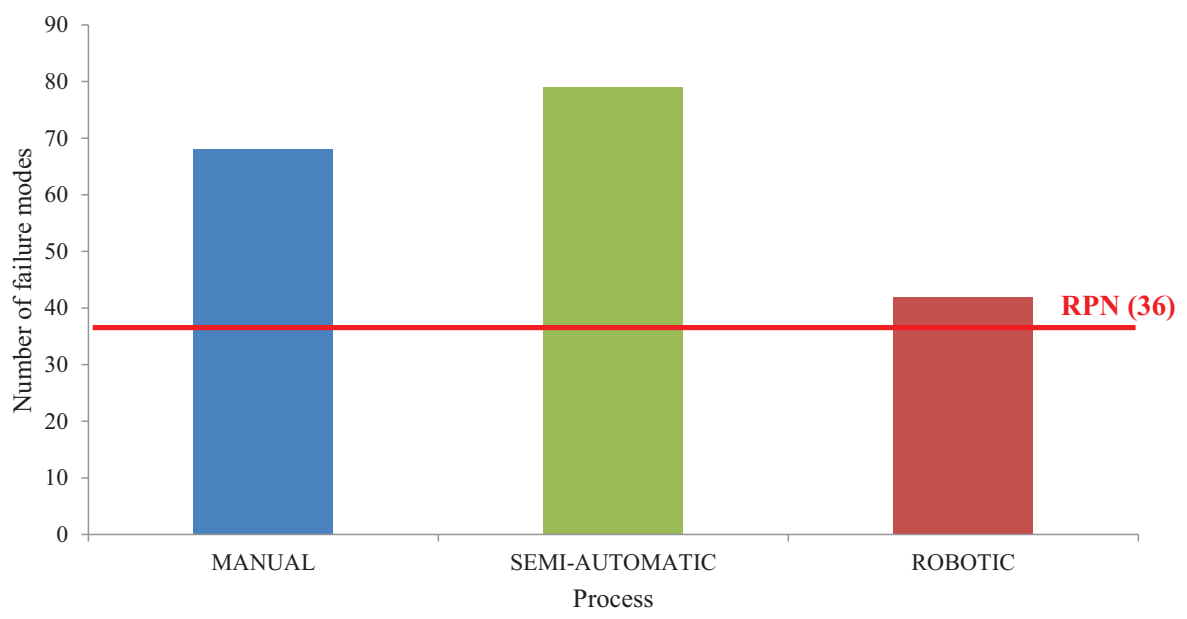

Figure 2: Number of failures modes according to the process. 


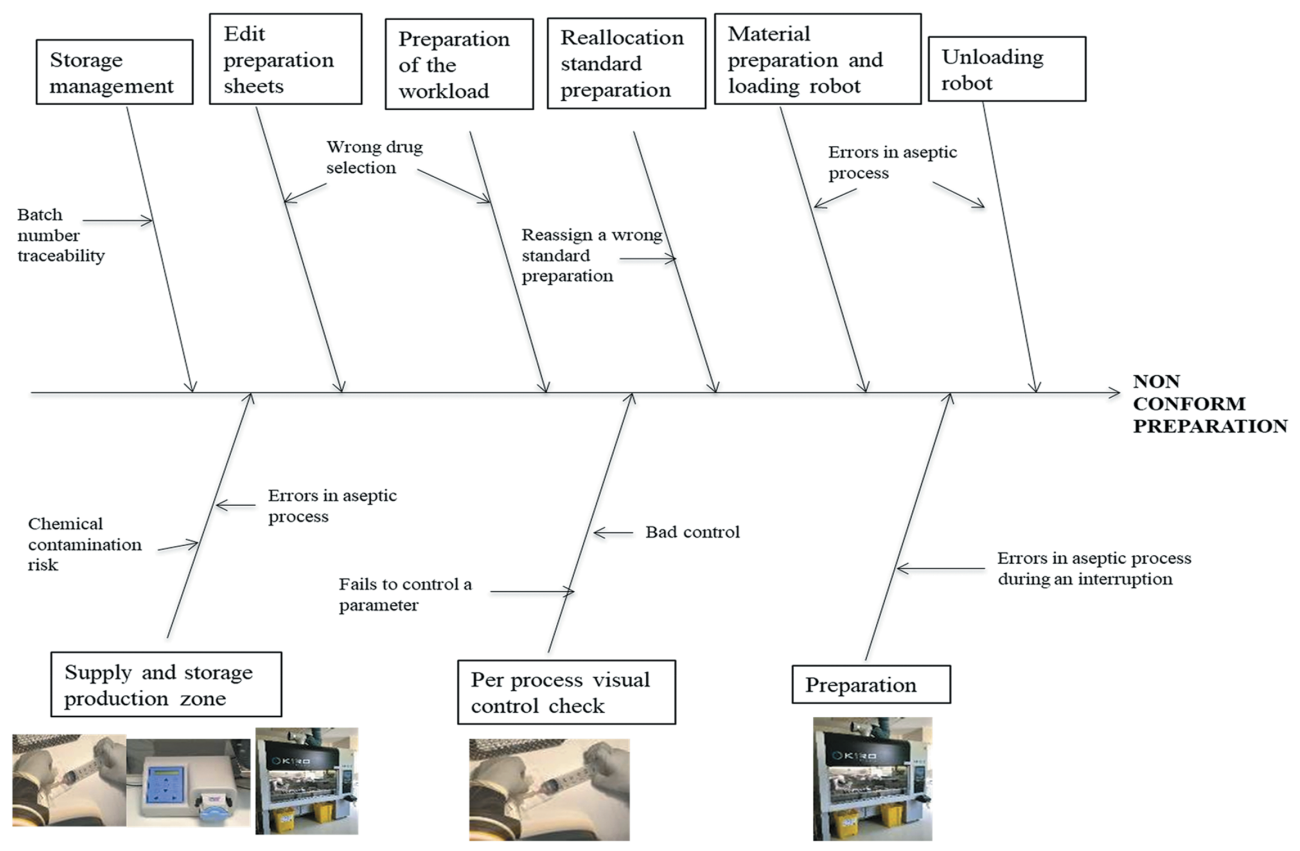

Figure 3: Ishikawa diagram of priority failure modes.

Table 3: Critical Indexes of priority failure modes.

\begin{tabular}{|c|c|c|c|c|c|c|}
\hline & Preparation Step & \multirow{2}{*}{$\begin{array}{l}\text { Failure } \\
\text { OCESSES (MANUAL, } \\
\text { ATIC, ROBOTIC) }\end{array}$} & \multicolumn{4}{|c|}{ Rating parameters } \\
\hline & $\begin{array}{l}\text { COMMON TO } 3 \text { PROCESSES (MANUAL, } \\
\text { SEMI-AUTOMATIC, ROBOTIC) }\end{array}$ & & 0 & $\mathbf{S}$ & D & $\mathrm{Cl}$ \\
\hline \multirow[t]{4}{*}{ Pre-process } & Storage management & Batch number traceability & 4 & 4 & 3 & 48 \\
\hline & \multirow[t]{2}{*}{ Supply and storage production zone } & Chemical contamination risk & 4 & 3 & 3 & 36 \\
\hline & & Errors in aseptic process & 4 & 3 & 3 & 36 \\
\hline & Edit preparation sheets & Wrong drug selection & 4 & 3 & 3 & 36 \\
\hline \multirow[t]{2}{*}{ Post-process } & Reallocation standard preparation & Reassign a wrong standard preparation & 3 & 4 & 3 & 36 \\
\hline & \multicolumn{2}{|c|}{ MANUAL PROCESS } & 0 & $\mathbf{S}$ & D & $\mathrm{Cl}$ \\
\hline Pre-process & Preparation of the workload & Wrong drug selection & 4 & 5 & 2 & 40 \\
\hline \multirow[t]{3}{*}{ Per-process } & Per process control visual check & Fails to control a parameter & 4 & 4 & 3 & 48 \\
\hline & Bad control & & 4 & 3 & 3 & 36 \\
\hline & \multicolumn{2}{|c|}{ ROBOTIC PROCESS } & 0 & $\mathbf{S}$ & D & $\mathrm{Cl}$ \\
\hline Pre-process & Preparation of the workload and loading robot & Errors in aseptic process & 4 & 3 & 3 & 36 \\
\hline Per-process & Preparation & $\begin{array}{l}\text { Errors in aseptic process during a technical } \\
\text { interruption }\end{array}$ & 4 & 3 & 3 & 36 \\
\hline Post-process & Unloading robot & Errors in aseptic process & 4 & 3 & 3 & 36 \\
\hline
\end{tabular}

O: Occurrence S: Severity D: Detectability Cl: Critically Index

the 3 processes together, $87.7 \%$ of the causes of the failure modes were mainly the result to a "Manpower" issue, $12.7 \%$ about a "Means/Materials" issue, 10.6\% about a "Environment" issue, 5.8\% about a "Material" issue and $3.2 \%$ about a "Method" issue. "Manpower" was always the first cause. "Environment" was the second cause for the manual process. In semi-automatic and robotic, "Means/ Materials" was the second cause. Their distributions are described in Figure 4. Examples cited by the working group are presented in Table 4.

In common with all processes, the human errors were the most involved in the analysis of cause identified. 


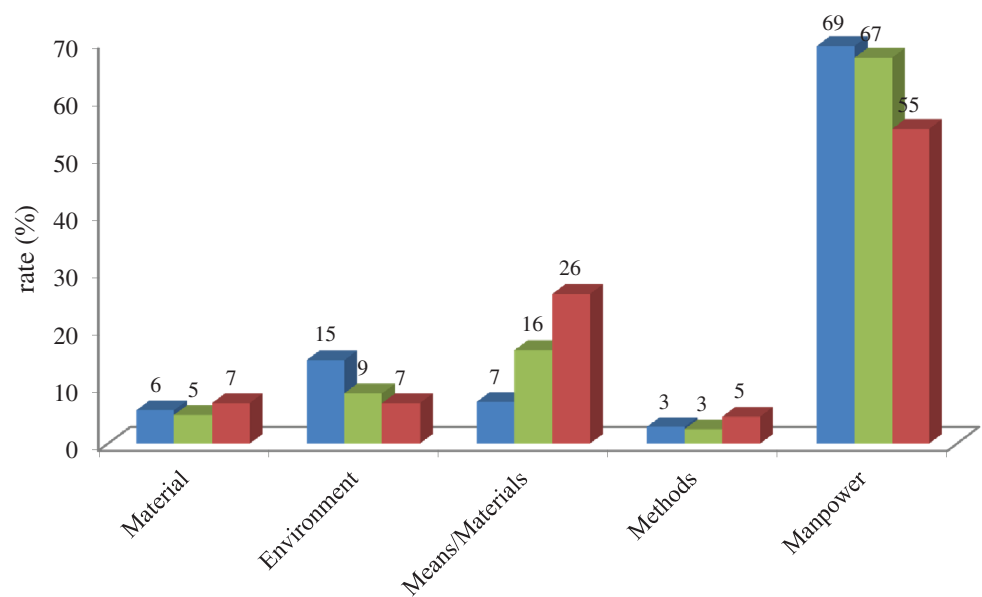

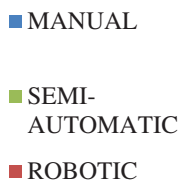

Figure 4: Distribution of per-process failure causes by categories.
Table 4: Examples of root causes.

\begin{tabular}{ll}
\hline TYPE OF CAUSES & EXAMPLES \\
\hline Manpower & Lack of training, tiredness, lack of time \\
Means/Materials & Technical failures \\
Environement & Lack of space, unsuitable organization \\
Material & Unsuitable storage management \\
Methods & Lack of education or protocol \\
\hline
\end{tabular}

In this category, forgetfulness, lack of training, tiredness and lack of time were most often mentioned by the working group. However, human factor was less important for the robotic process as it was independent of human for most of the preparation steps. On counterpart, with robotic or pump, the technical issues were the most identified. For manual process, apart of human error risks, working environment was the second cause identified i. e. lack of space or unsuitable organization.

\section{Establishing preventive measures}

Throughout the session 8, the work group worked on these 11 priority failure modes to find solutions and set up means of controlling the risk. Others were considered like acceptable or low priority because the risk was controlled. The reduction of the criticality index was based on two actions: either the reduction of the failure frequency that requires a change of organization, or the increase of the detectability of the failure by the implementation of a control. Examples of action plans are given in the Table 5. This last meeting session allowed a collegial and pragmatic reflection on the action plan. Finally, 19 failure modes were analyzed, and 31 actions were planned and monitoring indicators were built accordingly. The indicators for monitoring the actions planned were divided in common actions and specific actions related to the 3 different processes. In common actions, we identified education improvement, review and creation of quality documents and environmental microbiological and chemical monitoring. Related to automated processes, technical issues were the main issue to be followed. Among common indicators, one can cite:

- education monitoring indicators e. g. number of education program per year, number of operators educated per year. Number of operators passing a post-education exam (results $>80 \%$ of good answers). The ratio between the number of quality documents read by operators and the total number of quality document to be read.

- ratio between the number of quality documents written/ or revised and the total number of documents to be written/ or revised.

- Quantitative and qualitative collection and analysis of non-conformities.

Examples of actions planned and monitoring indicators thereof are given in Table 5.

Then, each action with the help of monitoring indicator were planned to be periodically reviewed to refine its relevance, feasibility, pilots and achievable deadlines with the pharmacists in charge of the production unit.

\section{Discussion}

Comparing the workflow organizations, the results showed that the worst case for productivity was the on-demand tailormade preparation. No difference was found in terms of productivity between manual and robot production, the lack of superiority of the robot process can be easily explained by the multiple in-process quality controls that are not carried out by technicians during the manual process [1]. 
Table 5: Examples of actions planned and their monitoring indicators.

\begin{tabular}{|c|c|c|c|}
\hline Preparation Step & Failure & Actions planned & Monitoring indicators \\
\hline & \multicolumn{3}{|c|}{ Common to 3 processes (manual, semi-automatic, robotic) } \\
\hline \multirow{2}{*}{$\begin{array}{l}\text { Entrance in } \\
\text { production area } \\
\text { and clothing }\end{array}$} & Zone pressure failure & $\begin{array}{l}\text { Daily control check list and pictogram } \\
\text { display with the reference value }\end{array}$ & $\begin{array}{l}\text { Number of pressure failure/ number of } \\
\text { pressure data collected }\end{array}$ \\
\hline & Incorrect clothing & Clothing procedure revision & $\begin{array}{l}\text { Number of positive microbiological } \\
\text { samples of operators'cloth / number of } \\
\text { operators' cloth sampled }\end{array}$ \\
\hline \multirow[t]{5}{*}{$\begin{array}{l}\text { Supplying storage } \\
\text { area }\end{array}$} & Chemical contamination risk & $\begin{array}{l}\text { Personal protective measures } \\
\text { education plan revision and staff } \\
\text { awareness }\end{array}$ & $\begin{array}{l}\text { Number of positive chemical samples } \\
\text { outside the collective protection } \\
\text { environment (isolator / BSC)/ total number } \\
\text { of chemical samples }\end{array}$ \\
\hline & & $\begin{array}{l}\text { Revision of frequency of the cleaning } \\
\text { process }\end{array}$ & $\begin{array}{l}\text { Number of operator per year who followed } \\
\text { new education program (cleaning - } \\
\text { clothing -chemical risk) / Number total of } \\
\text { operators to be educated }\end{array}$ \\
\hline & & $\begin{array}{l}\text { Review cleaning procedures and } \\
\text { education of the cleaning staff }\end{array}$ & $\begin{array}{l}\text { Number of operators who passed a post- } \\
\text { education exam (results }>80 \% \text { ) }\end{array}$ \\
\hline & $\begin{array}{l}\text { Errors in supplying controlled } \\
\text { areas (i. e. lack of glove port- } \\
\text { entering drug packaging) }\end{array}$ & $\begin{array}{l}\text { Specific handler education for gloving } \\
\text { procedure and packaging removal } \\
\text { outside controlled areas }\end{array}$ & Number of glove consumption/year \\
\hline & \multicolumn{3}{|c|}{ Manual process } \\
\hline $\begin{array}{l}\text { Preparation of the } \\
\text { workload }\end{array}$ & Wrong drug selection & $\begin{array}{l}\text { Implement automatized in process } \\
\text { control (e. g. camera recognition and } \\
\text { recording) }\end{array}$ & $\begin{array}{l}\text { Qualitative and quantitative collection and } \\
\text { analysis of non-conformities }\end{array}$ \\
\hline $\begin{array}{l}\text { Per process control } \\
\text { visual check }\end{array}$ & $\begin{array}{l}\text { Fails to control a parameter or } \\
\text { bad control }\end{array}$ & $\begin{array}{l}\text { Implement automatized in process } \\
\text { control (e. g. gravimetric and/or } \\
\text { camera recognition) }\end{array}$ & $\begin{array}{l}\text { Date of implementation of the new } \\
\text { technology }\end{array}$ \\
\hline \multirow[t]{2}{*}{$\begin{array}{l}\text { Reallocation for } \\
\text { standard } \\
\text { preparation }\end{array}$} & $\begin{array}{l}\text { Reassign a wrong standard } \\
\text { preparation }\end{array}$ & $\begin{array}{l}\text { Development of a new software } \\
\text { functionality }\end{array}$ & $\begin{array}{l}\text { Date of implementation of the new } \\
\text { functionality of the software }\end{array}$ \\
\hline & \multicolumn{3}{|c|}{ Robotic process } \\
\hline \multirow[t]{2}{*}{$\begin{array}{l}\text { Pre-process / per- } \\
\text { process loading } \\
\text { in PSB }\end{array}$} & Errors of aseptic gloving & $\begin{array}{l}\text { Revision of the sterile gloves port } \\
\text { protocol }\end{array}$ & $\begin{array}{l}\text { Date of creation of a new education program } \\
\text { Number of operators who passed a post- } \\
\text { education exam (results }>80 \% \text { ) }\end{array}$ \\
\hline & \multicolumn{3}{|c|}{ Semi-automatic process } \\
\hline $\begin{array}{l}\text { Batch matrix and } \\
\text { labels printing }\end{array}$ & $\begin{array}{l}\text { Errors in batch number } \\
\text { selection }\end{array}$ & $\begin{array}{l}\text { IT system with supervision software } \\
\text { for batch checking }\end{array}$ & $\begin{array}{l}\text { Qualitative and quantitative collection and } \\
\text { analysis of non-conformities }\end{array}$ \\
\hline $\begin{array}{l}\text { Preparation of the } \\
\text { workload }\end{array}$ & Errors in device/drug selection & $\begin{array}{l}\text { IT system with supervision software } \\
\text { for drug and device selection }\end{array}$ & $\begin{array}{l}\text { Date of implementation of the new IT } \\
\text { system }\end{array}$ \\
\hline Bulk bag preparation & $\begin{array}{l}\text { Missing a step (wrong drug, } \\
\text { wrong quantity) }\end{array}$ & $\begin{array}{l}\text { IT system with supervision software for } \\
\text { identification and quantification of drug }\end{array}$ & \\
\hline Final bag preparation & $\begin{array}{l}\text { Missing a step (wrong final } \\
\text { volume) }\end{array}$ & $\begin{array}{l}\text { IT system with supervision software } \\
\text { for control the individual final weight }\end{array}$ & \\
\hline
\end{tabular}

The best for productivity was the standard preparations and among the different processes, the standard preparation from a bulk solution using a peristaltic pump gave the best results in comparison to the robot. However, when the robot workflow was fairly optimized with standard preparations, its productivity was dramatically improved and confirmed our first results [17]. Moreover, our results were similar to productivity results obtained with other robots such as PharmaHelp $^{\circledR}$ where authors found a productivity of 10 bags for 60 min44 sec [18] or with APOTECAchemo ${ }^{\circledR}$ robot, where average time of a preparation from a ready-to-use drug was $5.57 \mathrm{~min}$ or $6.11 \mathrm{~min}$ from a drug to be reconstituted [7].

For Masini et al [19], on a productivity point of view, the robotic process was interesting for a volume superior to 34 000 preparations per year, however the market is still in progress and depending on the different designs of the robots this limit may be questionable. Nevertheless, automation cannot be reduced to the unique benefit for productivity 
and is a real opportunity to secure the process. All process conditions including tailor-made took great benefit of robotics in comparison to usual human double check.

The major interest of FMECA method was it helped the team to identify the priority failure modes to decide and prioritize actions to be taken. Moreover, the active discussions necessary to find corrective actions contributed to the development of a safety culture and helped to move toward to a management system through quality. This method had also increased staff vigilance in the face of emerging dysfunctions. The subjectivity can be considered as the drawback of the FMECA method [8]. Indeed, the quantification is not the goal of the method, but most likely identification of failure modes and their relative ratings based on the perception of the risk by professional. That is why it was important to mix different professional from different academic sources. To reduce this bias, we were able to create multidisciplinary group including health manager, pharmacist and pharmaceutical technicians. During the training session, it was clarified with the working group that the exact score defined to rate a risk was not essential because the main objective was to carry out a risk prioritization [15].

The FMECA risk analysis study helped us to clearly determine the strength and weakness of the different processes. Manual process was as expected the most at risk with the maximum $\mathrm{CI}$ score. However, the process mapping allowed to clearly identify that the semi-automatic process included the most sub-steps than other processes which may be pejorative as it is known that important sub-steps led to an increase of failure modes $[9,15]$. At the opposite, the robot was the process leading to the less sub-steps and exhibited the less failure modes. Action plans was mainly highlighting the need for specific educational plan dedicated to the automated process and for some policies revisions which was considered as easy measures and low-cost measures to be implemented. Besides low-cost measures, higher cost measures were identified by the group to secure the per-process both for manual and semi-automatic process. In our routine for both systems we already implemented a post-process analytical identification and quantification on the endproduct. But analytical control is not available for all drugs leading to the need to implement per-process control. The benefits and limits of per-process and post process controls were extensively discussed by Lagarce [20], When per-process control is based on human double-check the reliability of the method is limited to $85 \%$ [21] and encourages even for tailor-made preparations the use of robotic which integrates multiple per-process controls (camera recording and gravimetric control).
Considering the semi-automatic process, without IT system piloting the process, the identification and quantification of the bulk mixture by analytical controls and the gravimetric control of the final bags prepared were satisfactory methods to fully secure the process. However, it exposes to the risk of destruction of the full batch in case of errors not detected during per-process. That is why, additional IT system piloting the pump was purposed by the FMECA analysis. In the same way for the manual process, IT system piloting the per-process was also suggested by implementing either camera recording [22] and/or gravimetry [18] software to substitute advantageously the human double check.

\section{Conclusion}

Automation of the process is giving new perspective for the preparation of injectable drugs in hospital pharmacies, the benefit and the limits have to be fully investigated by combining productivity and risk analysis assessment. Semi-automatic process is interesting to prepare batches of the same drug and standard dose following a process more likely conform to pharmaceutical industry giving the highest productivity but with some weakness considering the in-process quality control. Besides, robot, even for "on demandz tailor-made preparation, was more efficient than manual process because it improved reliability of controls giving higher quality level and less failure modes. Our results are in accordance with the fact that robot is able to dramatically reduce the human errors than cannot be fully controlled even with a safety system management because of the known human limited reliability in control and specially when human is involved in repetitive tasks. This work highlighted the interest of automation with the need to adapt our organizations to the robotics i. e to develop standardized preparations to improve productivity and to be able to capitalize on this emerging technology securing the process.

Acknowledgements: The authors would like to thank for their technical assistance : Technician team from KIRO Oncology Grifols, Valérie Moreno from the Biomedical department CHU de Bordeaux, Céline Santos from the IT department CHU de Bordeaux.

Conflict of interest statement: The authors state no conflict of interest. The authors have read the journal's Publication ethics and publication malpractice statement available at the journal's website and hereby confirm that they comply with all its parts applicable to the present scientific work. 


\section{Appendix}

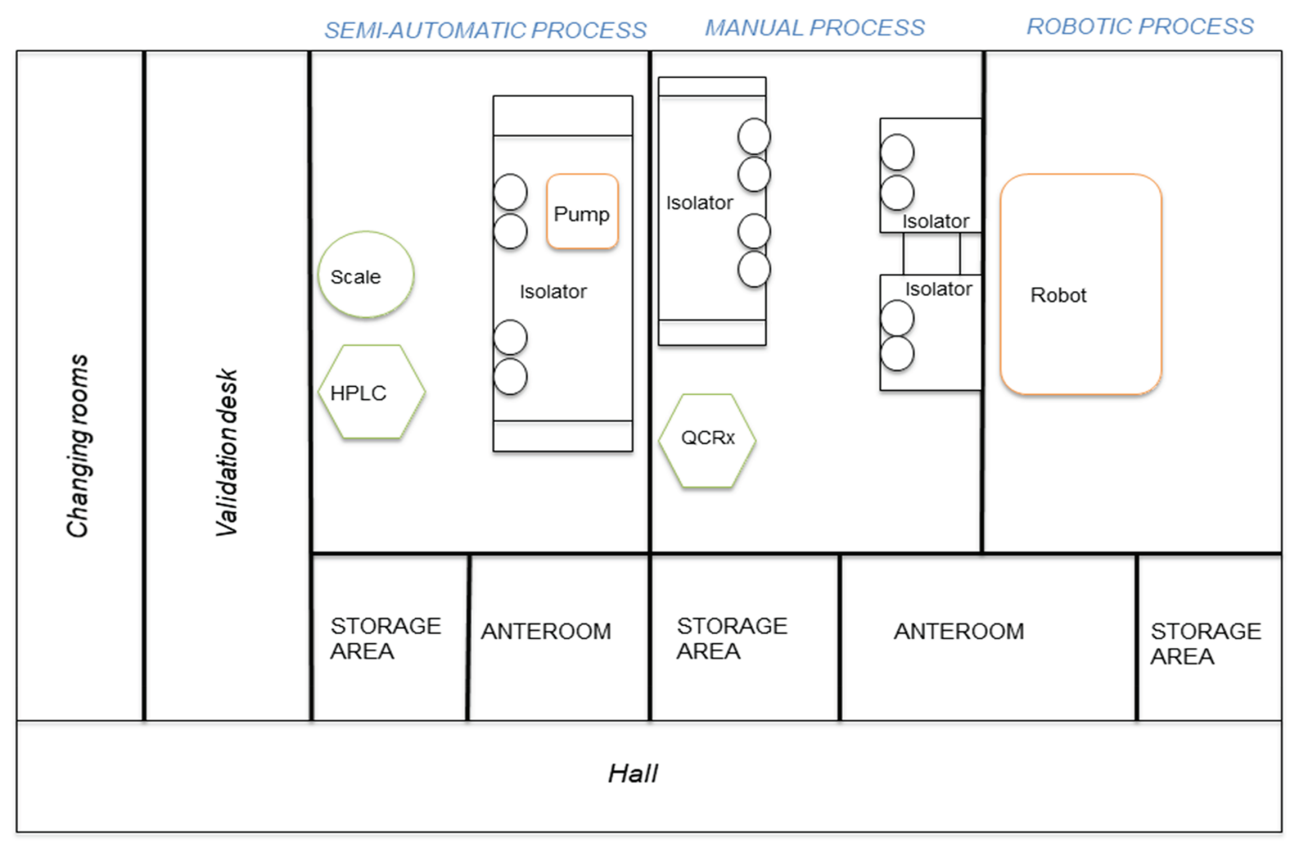

Figure 5: Schematic representation of centralized reconstitution unit.

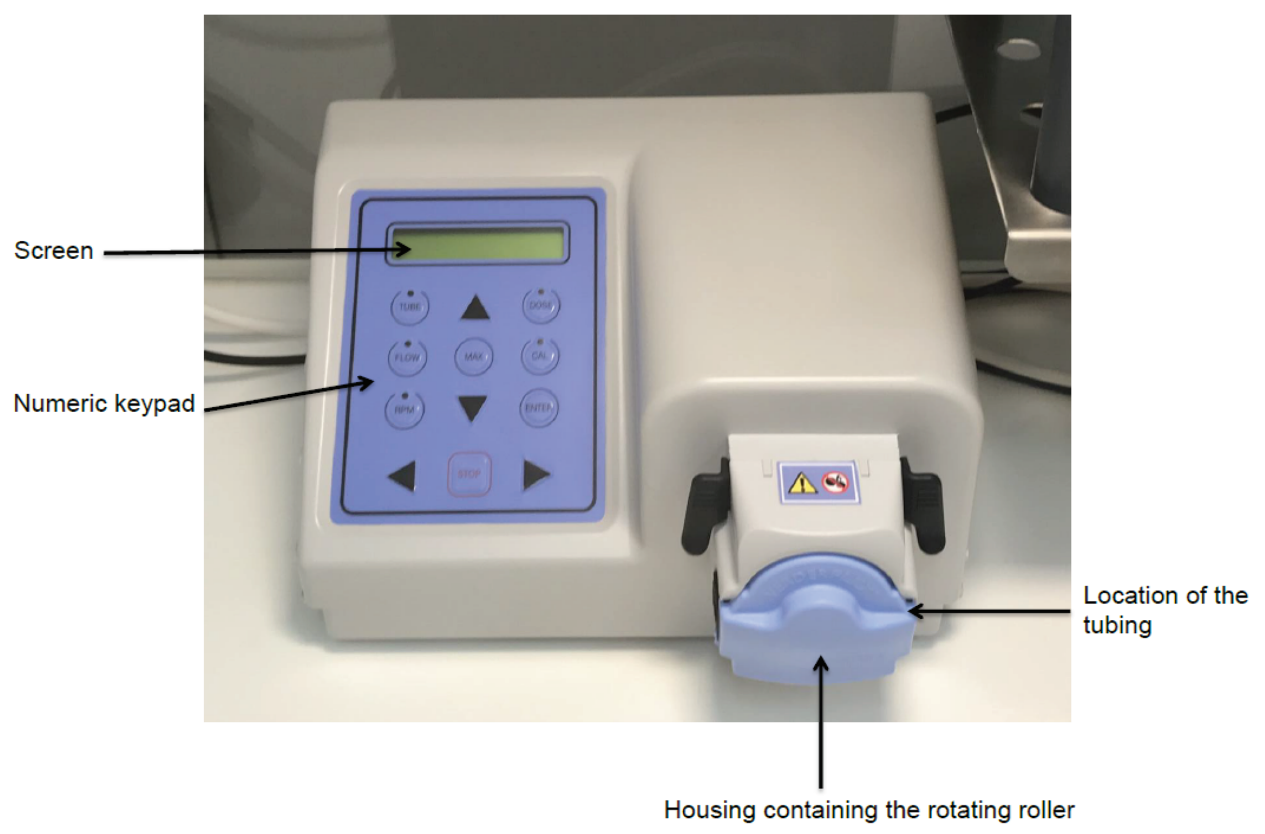

Figure 6: Photography of the Verderflex ${ }^{\circledR}$ pump. 

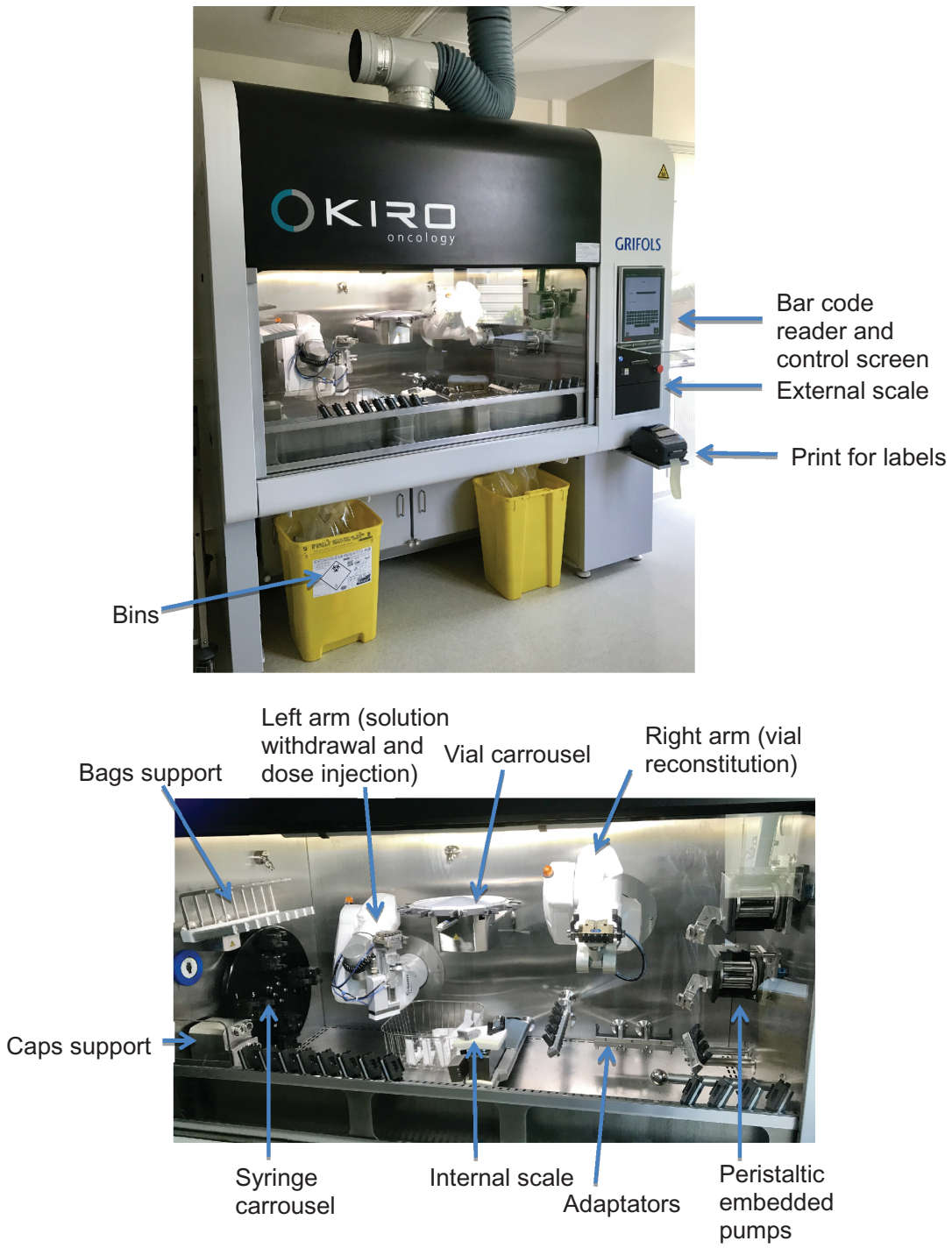

Figure 7: Pictures of the $\mathrm{KIRO}^{\circledR}$ Oncology robot.

\section{References}

[1] Carrez L, Falaschi L, Cingria L, Sadeghipour F, Bouchoud L, Bonnabry P. Organisation et sécurisation du circuit des chimiothérapies: exemple de la pharmacie des Hôpitaux Universitaires de Genève. Pharmactuel 2014;47:119-24.

[2] Iwamoto T, Morikawa T, Hioki M, Sudo H, Paolucci D, Okuda M. Performance evaluation of the compounding robot, APOTECAchemo, for injectable anticancer drugs in a Japanese hospital. J Pharm Heal Care Sci 2017;3:12.

[3] Société Française de Pharmacie Oncologique. Adaptations des ressources liées à la pharmacie oncologique Edition $\mathrm{N}^{\circ} \mathrm{1}$ Octobre 2012. [Internet]. 2012. Available at: https://www.sfpo. com/wp-content/uploads/2012/10/Recommandations_vf_ hmPDFCreator.pdf

[4] Seger AC, Churchill WW, Keohane CA, Belisle CD, Wong ST, Sylvester KW, et al. Impact of robotic antineoplastic preparation on safety, workflow, and costs. J Oncol Pract 2012;8:344-9.
[5] Schierl R, Masini C, Groeneveld S, Fischer E, Bohlandt A, Rosini V, et al. Environmental contamination by cyclophosphamide preparation: comparison of conventional manual production in biological safety cabinet and robot-assisted production by APOTECAchemo. J Oncol Pharm Pract 2016;22:37-45.

[6] Reisz F, Gairard-Dory AC, Fonmartin K, Bourbon BG J. Prévention des troubles musculo squelettiques en pharmacotechnie [Internet]. GERPAC. 2016. Available at: https://www. gerpac.eu/prevention-des-troubles-musculo-squelettiques-enpharmacotechnie

[7] Carrez L, Martin V, Verrey AS, Furrer P, Bouchoud L, Falaschi L, et al. Qualification and performance evaluation of an automated system for compounding injectable cytotoxic drugs. Pharm Technol Hosp Pharm 2018 Aug 28;3:165-75.

[8] Bonan B, Martelli N, Berhoune M, Maestroni M-L, Havard L, Prognon P. The application of hazard analysis and critical control points and risk management in the preparation of anticancer drugs. Int J Qual Health Care 2009;21:44-50. 
[9] Bonnabry P, Cingria L, Sadeghipour F, Ing H, Fonzo-Christe C, Pfister RE. Use of a systematic risk analysis method to improve safety in the production of paediatric parenteral nutrition solutions. Qual Saf Health Care 2005 Apr 1;14:93-8.

[10] Plumridge RJ, Sewell GJ. Dose-banding of cytotoxic drugs: a new concept in cancer chemotherapy. Am J Heal Pharm 2001;58:1760-4.

[11] Agence nationale de sécurité du médicament. Bonnes pratiques de préparation. Bull off 2007;33:1-79.

[12] Sauvaget L Standardisation des doses (ou Dose-Banding) des médicaments injectables: application à deux principes actifs l'aciclovir et l'infliximab [Internet]. 2016. Available at: https://dumas.ccsd.cnrs.fr/dumas-01310879

[13] Bonnabry P, Cingria L, Ackermann M, Sadeghipour F, Bigler L, Mach N. Use of a prospective risk analysis method to improve the safety of the cancer chemotherapy process. Int J Qual Heal Care 2006;18:9-16.

[14] Boulé M, Lachapelle S, Collin-Lévesque L, Demers É, Nguyen C, Lebel D, et al. Approche commentée par étape pour réaliser une AMDEC dans le cadre du circuit du médicament. Le Pharm Hosp Clin 2018;53:315-24.

[15] Bonnabry P, Despont-Gros C, Grauser D, Casez P, Despond M, Pugin D, et al. A risk analysis method to evaluate the impact of a computerized provider order entry system on patient safety. J Am Med Informatics Assoc 2008;15:453-60.

[16] Haute Autorité de Santé. La sécurité des patients: mettre en œuvre la gestion des risques associés aux soins en établissement de santé - Des concepts à la pratique. 2012;220. Available at: http://www.has-sante.fr/portail/upload/docs/ application/pdf/2012-04/okbat_guide_gdr_03_04_12.pdf

[17] Deljehier T, Bougueon G, Heloury J, Moreno V, Berroneau A, Crauste-Manciet S. Simulation program of a cytotoxic compounding robot for monoclonal antibodies and antiinfectious sterile drug preparation. J Oncol Pharm Pract 2019; in press. doi.org/10.1177/1078155218823911

[18] Carrez L, Bouchoud L, Fleury-Souverain S, Combescure C, Falaschi L, Sadeghipour F, et al. Reliability of chemotherapy preparation processes: evaluating independent double-checking and computer-assisted gravimetric control. J Oncol Pharm Pract 2017;23:83-92.

[19] Masini C, Nanni O, Antaridi S, Gallegati D, Marri M, Paolucci D, et al. Automated preparation of chemotherapy: quality improvement and economic sustainability. Am J Heal Syst Pharm 2014;71:579-85.

[20] Lagarce F. Centrally prepared cytotoxic drugs: what is the purpose of their quality control? Pharm Technol Hop Pharm 2017;2:29-33.

[21] Facchinetti NJ, Campbell GM, Jones DP. Evaluating dispensing error detection rates in a hospital pharmacy. Medical Care 1999;37:39-43.

[22] Benizri F, Dalifard B, Zemmour C, Henriquet M, Fougereau E, Le Franc B. DrugCam ${ }^{\circledR}-$ An intelligent video camera system to make safe cytotoxic drug preparations. Int J Pharm 2016;502:198-207. 